\title{
Identification of Multiple Phytotoxins Produced by Fusarium virguliforme Including a Phytotoxic Effector (FvNIS1) Associated With Sudden Death Syndrome Foliar Symptoms
}

\author{
Hao-Xun Chang, ${ }^{1}$ Leslie L. Domier, ${ }^{1,2}$ Osman Radwan, ${ }^{1}$ Craig R. Yendrek, ${ }^{1,3}$ Matthew E. Hudson, ${ }^{1}$ and \\ Glen L. Hartman ${ }^{1,2}$ \\ ${ }^{1}$ University of Illinois; ${ }^{2}$ USDA-Agricultural Research Service; and ${ }^{3}$ Institute for Genomic Biology, Urbana, IL, U.S.A. \\ Submitted 27 September 2015. Accepted 27 November 2015.
}

Sudden death syndrome (SDS) of soybean is caused by a soilborne pathogen, Fusarium virguliforme. Phytotoxins produced by $F$. virguliforme are translocated from infected roots to leaves, in which they cause SDS foliar symptoms. In this study, additional putative phytotoxins of $F$. virguliforme were identified, including three secondary metabolites and 11 effectors. While citrinin, fusaric acid, and radicicol induced foliar chlorosis and wilting, Soybean mosaic virus (SMV)-mediated overexpression of $F$. virguliforme necrosis-inducing secreted protein 1 (FvNIS1) induced SDS foliar symptoms that mimicked the development of foliar symptoms in the field. The expression level of fvnis 1 remained steady over time, although foliar symptoms were delayed compared with the expression levels. SMV::FvNIS1 also displayed genotypespecific toxicity to which 75 of 80 soybean cultivars were susceptible. Genome-wide association mapping further identified three single nucleotide polymorphisms at two loci, where three leucine-rich repeat receptor-like protein kinase (LRR-RLK) genes were found. Culture filtrates of fvnis 1 knockout mutants displayed a mild reduction in phytotoxicity, indicating that FvNIS1 is one of the phytotoxins responsible for SDS foliar symptoms and may contribute to the quantitative susceptibility of soybean by interacting with the LRR-RLK genes.

Plant-pathogenic fungi produce a variety of phytotoxins that could be classified into host-selective toxins (HST) and nonHST. While non-HST indiscriminately attack a broad range of hosts, HST are small molecules produced by necrotrophic

Mention of a trademark, proprietary product, or vendor does not constitute a guarantee or warranty of the product by the United States Department of Agriculture or the University of Illinois and does not imply its approval to the exclusion of other products or vendors that may also be suitable.

Nucleotide sequence data is available in the DDBJ/EMBL/GenBank databaseunder accession number GBJV01000000.

Corresponding author: G. L. Hartman; Telephone: +1.217.244.3258; E-mail: ghartman@illinois.edu

*The $\boldsymbol{e}$-Xtra logo stands for "electronic extra" and indicates that six supplementary figures and seven supplementary tables are published online.

This article is in the public domain and not copyrightable. It may be freely reprinted with customary crediting of the source. The American Phytopathological Society, 2016. pathogens that damage only certain genotypes of plants having corresponding susceptibility alleles (Stergiopoulos et al. 2013). The interaction of pathogens carrying a susceptibility allele results in susceptibility that is also known as the inverse gene-forgene model (Vleeshouwers and Oliver 2014). The pathosystem of Parastagonospora nodorum and wheat is a well-studied example of how pathogens utilize phytotoxic (or necrotrophic) effectors to achieve host susceptibility (Oliver et al. 2012; Vleeshouwers and Oliver 2014). The arsenal of Parastagonospora nodorum includes eight effectors (SnTox1 to SnTox7 as well as SnToxA) that generally induce chlorosis or necrosis symptoms in wheat cultivars that have corresponding susceptible quantitative trait loci (QTL), including Snn1 to Snn7 and Tsn1 (Abeysekara et al. 2012; Friesen and Faris 2010; Friesen et al. 2007; Liu et al. 2009; Oliver et al. 2012; Shi et al. 2015). For SnTox1-Snn1 and SnToxA-Tsn1, the candidate target genes in wheat encode leucine-rich repeat (LRR) domain proteins, it was suggested that SnTox1 and SnToxA induce the accumulation of reactive oxygen species and programmed cell death through LRR-dependent signaling pathways to achieve effector-triggered susceptibility (Faris et al. 2010; Liu et al. 2012).

Sudden death sydrome (SDS) of soybean [Glycine max (L.) Merr.] is one of the most important fungal diseases of soybean in the United States (Hartman et al. 2015) and is caused by the root-infecting pathogen Fusarium virguliforme (Aoki et al. 2003; Hartman et al. 2015). In the field, the pathogen infects roots but is not known to invade above-ground parts of soybean plants. In addition to root rot, $F$. virguliforme can elicit distinct foliar symptoms that "suddenly" appear after the onset of flowering. These foliar symptoms include interveinal chlorosis and necrosis, marginal curling of leaflets, and premature defoliation (Supplementary Fig. S1), and are attributed to fungal phytotoxins that are translocated to leaves from colonized roots (Hartman et al. 2015). Three phytotoxins have been reported to be associated with SDS foliar symptoms, but none of the three induce foliar symptoms that represent the foliar symptoms observed in the field. Radicicol (also known as monorden) was the first $F$. virguliforme phytotoxin identified and was proposed to cause interveinal necrosis and marginal curling on soybean (Baker and Nemec 1994). The second phytotoxin identified from $F$. virguliforme was a $17-\mathrm{kDa}$ effector that induced chlorosis and necrosis on soybean cotyledons and detached leaves (Jin et al. 1996). FvTox1, the third F. virguliforme phytotoxin identified, was also an effector that induced chlorosis and reduced the chlorophyll content of leaf disks treated with purified FvTox1 (Brar et al. 2011). Knockout mutants of FvTox1 were 
substantially reduced in phytotoxicity but $\Delta$ fvtoxl mutants were still able to induce SDS foliar symptoms (Pudake et al. 2013), suggesting that additional phytotoxins may be causing SDS foliar symptoms.

Chromatography coupled with bioassay systems have been traditionally used to discover phytotoxins produced in vitro (Berestetskiy 2008; Strange 2007), and all three known phytotoxins of $F$. virguliforme were identified using chromatography. Another approach to discovering secondary metabolites and secretory effectors is through bioinformatics. This strategy enables the discovery of phytotoxins that have low or trace quantities in the sample and avoids potential loss during chemical extraction or chromatographic steps. Many studies have demonstrated the potential of predicting secondary metabolites and secretory effectors (Chooi and Tang 2012; Collemare et al. 2014; Gallo et al. 2013; Kimura et al. 2007; Knief 2014; Kroken et al. 2003; Sperschneider et al. 2015; Yadav et al. 2009). In this study, we identified additional phytotoxins of $F$. virguliforme by searching for genes potentially involved in synthesizing secondary metabolites or encoding phytotoxic effectors. The goal was to identify and characterize additional phytotoxins produced by $F$. virguliforme that were associated with SDS foliar symptoms.

\section{RESULTS}

\section{Transcriptome analysis.}

Cell-free culture filtrates of $F$. virguliforme have been shown to induce typical SDS foliar symptoms and studies have shown that phytotoxicity of the culture filtrates increased with the in vitro growth time of $F$. virguliforme (Hartman et al. 2004; Xiang et al. 2015). Since RNA-Seq reflects gene expression at one sampling time, identification of phytotoxin-related genes was conducted based on a transcriptome derived from two in vitro incubation periods in order to maximize detection of phytotoxin-related gene expression. Six sequence libraries (Supplementary Table S1) with a call accuracy of $99.9 \%$ were assembled into a transcriptome with 12,858 putative coding sequences. The transcriptome shotgun assembly was deposited at $\mathrm{DDBJ} / \mathrm{EMBL} / \mathrm{GenBank}$ databaseunder accession number GBJV01000000.

\section{Identification and characterization of phytotoxic secondary metabolites.}

The transcriptome contained 12 putative polyketide synthases (PKS). Based on the phylogenetic analysis, fvpks 1 and fvpks2 were grouped in the same clade containing PKS of Chaetomium chiversii (rads 2 and radsl, respectively) and PKS of $F$. graminearum ( $p k s l$ and $p k s 4$, respectively); these PKS synthesize structurally similar resorcylic acid lactones, radiciol, and zearalenone (Table 1; Fig. 1). The PKS fvpks3 was grouped with pksCT of Monascus purpureus (synthesizes citrinin), with a bootstrap value of 99. The PKS fvpks4 was similar to fubl of F. verticillioides (synthesizes fusaric acid), with a bootstrap value of 96 . The fvpks5 was grouped with Alternaria alternata aft $9-1$ (synthesizes AF-toxin), with a bootstrap value of 61. The fupks6 was grouped with pks 2 of Cochliobolus heterostrophus (synthesizes T-toxin), with a bootstrap value of 66. Although both fvpks 7 and fvpks8 received a high bootstrap value of 99 , they were close to PKS genes that produce pigments such as fusarubin. While fvpks 9 formed a singleton, fvpks 10 and $f v p k s 11$ were similar to fuml of $F$. oxysporum and $F$. verticillioides (synthesizes fumonisin), with a bootstrap value of 99. In addition, fvpks 12 was highly similar to the fatty acid synthase outgroup. In summary, six $F$. virguliforme PKS were highly similar to other fungal PKS that synthesize citrinin, fumonisin, fusaric acid, and radicicol (Table 1; Fig. 1). Using commercially available citrinin, fumonisin, fusaric acid, and radicicol as standards, liquid chromatography-tandem mass spectrometry (LC/MS/MS) confirmed the presence of citrinin, fusaric acid, and radicicol but not fumonisin in the culture filtrates of $F$. virguliforme. The concentration of citrinin, fusaric acid, and radiciol was $0.07 \pm 0.01,2.03 \pm 0.34$, and $1,740.00 \pm 603.57 \mathrm{ng}$ per $\mathrm{ml}$ in 5-day-old culture filtrates and $0.25 \pm 0.05,2.51 \pm 1.10$, and 1,596.67 $\pm 507.73 \mathrm{ng}$ per $\mathrm{ml}$ in 2-day-old culture filtrates, respectively. Gene expression of these PKS was detected by quantitative reverse-transcription polymerase chain reaction (qRT-PCR) from 0 to $120 \mathrm{~h}$ after inoculation (hai) on soybean roots inoculated with $F$. virguliforme (Supplementary Fig. S2). Soybean leaves treated with a serial concentration of each polyketide revealed a minimum dosage of 60,20 , and $250 \mu \mathrm{g}$ per plant for citrinin, fusaric acid, and radicicol, respectively, to induce symptoms such as interveinal chlorosis and wilting 3 days postinoculation (dpi) (Fig. 2).

There were seven putative nonribosomal peptide synthetases (NRPS) identified in the transcriptome (Table 1), but the result indicated most NRPS of $F$. virguliforme were dissimilar to most fungal NRPS that we included in the phylogenetic analysis (Supplementary Fig. S3) and putative products of FvNRPS were less predictable. In addition, we did not detect the expression of trichodiene synthase, a key enzyme in trichothecene biosynthesis (Kimura et al. 2007). Although trichothecene is a distinct group found in several Fusarium species (Yekkour et al. 2015), our preliminary screen for trichothecenes was negative in culture filtrates of $F$. virguliforme, infested sorghum, and in infected soybean (Supplementary Table S2).

Identification and characterization of phytotoxic effectors.

Eleven putative phytotoxic effectors were identified by searching small secretory proteins in the transcriptome (Table 2). In addition to fvtoxl, another gene that encodes the second phytotoxin of $F$. virguliforme (Jin et al. 1996) was identified, based on a high degree of similarity to the $\mathrm{N}$ terminal peptide sequence ATQFSYTGSCTGTDQ with a mismatch (E to $\mathrm{C}$ ) at the tenth amino acid. We named this effector FvTox2. Three candidate effectors, FvCP1 to FvCP3, belonging to the cerato-platanin protein family were identified (Frías et al. 2014). Another potential effector, FvCDIP1, was orthologous to the Magnaporthe oryzae cell death-inducing protein MoCDIP1 (Chen et al. 2013). Moreover, we identified

Table 1. Identification of polyketide synthases (PKS) and nonribosomal peptide synthetases (NRPS) of Fusarium virguliforme

\begin{tabular}{lllc}
\hline Name & Gene ID & \multicolumn{1}{c}{ Putative metabolites } & Bootstrap value \\
\hline PKS & & & \\
fvpks1 & $\mathrm{g} 9470$ & Radicicol & 76 \\
fvpks2 & $\mathrm{g} 9476$ & Radicicol & 92 \\
fvpks3 & $\mathrm{g} 15275$ & Citrinin & 99 \\
fvpks4 & $\mathrm{g} 3064$ & Fusaric acid & 96 \\
fvpks5 & $\mathrm{g} 7866$ & AF-toxin-close product & 61 \\
fvpks6 & $\mathrm{g} 11035$ & T-toxin-close product & 66 \\
fvpks7 & $\mathrm{g} 13193$ & Fusarubin-close pigment & 99 \\
fvpks8 & $\mathrm{g} 15010$ & Perithecial pigment & 99 \\
fvpks9 & $\mathrm{g} 11834$ & Unknown & - \\
fvpks10 & $\mathrm{g} 1692$ & Fumonisin-close product & 99 \\
fvpks11 & $\mathrm{g} 15266$ & Fumonisin-close product & 99 \\
fvpks12 & $\mathrm{g} 12965$ & Fatty acid-close product & 99 \\
NRPS & & & \\
fvnrps1 & $\mathrm{g} 9648$ & Siderophore-close product & $99-100$ \\
fvnrps2 & $\mathrm{g} 5038$ & Unknown & - \\
fvnrps3 & $\mathrm{g} 4177$ & Unknown & - \\
fvnrps4 & $\mathrm{g} 2980$ & Unknown & - \\
fvnrps5 & $\mathrm{g} 2743$ & Unknown & - \\
fvnrps6 & $\mathrm{g} 2085$ & Unknown & - \\
fvnrps7 & $\mathrm{g} 64$ & Unknown & \\
\hline
\end{tabular}


four effectors (FvNLP1 to FvNLP4) that contained NPP1 domains that belong to necrosis and ethylene-inducing likeproteins (NLP) (Oome and Van den Ackerveken 2014) and one effector, $F$. virguliforme necrosis-inducing secreted protein 1 (FvNIS1), that was orthologous to Colletotrichum orbiculare NIS1, which induces necrosis on tobacco (Yoshino et al. 2012). The expression of these candidate effectors were detected by qRT-PCR from 0 to 120 hai on soybean roots inoculated with $F$. virguliforme. To characterize their phytotoxicity on soybean leaves, putative phytotoxic effectors were expressed ectopically in susceptible soybean cultivar Essex, using an overexpression system mediated by Soybean mosaic virus (SMV). FvTox1, FvTox2, FvCP1-2, FvCDIP1, and FvNLP1 to FvNLP4 did not induce SDS-like foliar symptoms.
However, plants inoculated with SMV::FvNIS1 induced typical SDS foliar symptoms (Fig. 3). Severely affected plants also exhibited upward curling of leaf margins and defoliation. In brief, overexpression of SMV::FvNIS1 in soybean produced SDS foliar symptoms indistinguishable to foliar symptoms observed in the field.

\section{Phytotoxicity of SMV::FvNIS1 at different time points and on different soybean genotypes.}

Symptom development on leaves of cultivar Essex started as mild chlorotic and necrotic spots at $20 \mathrm{dpi}$. Foliar symptoms became more pronounced and developed into interveinal chlorosis and necrosis after 30 to 40 dpi (Fig. 4). The healthy soybean control, soybean inoculated with empty SMV vector,

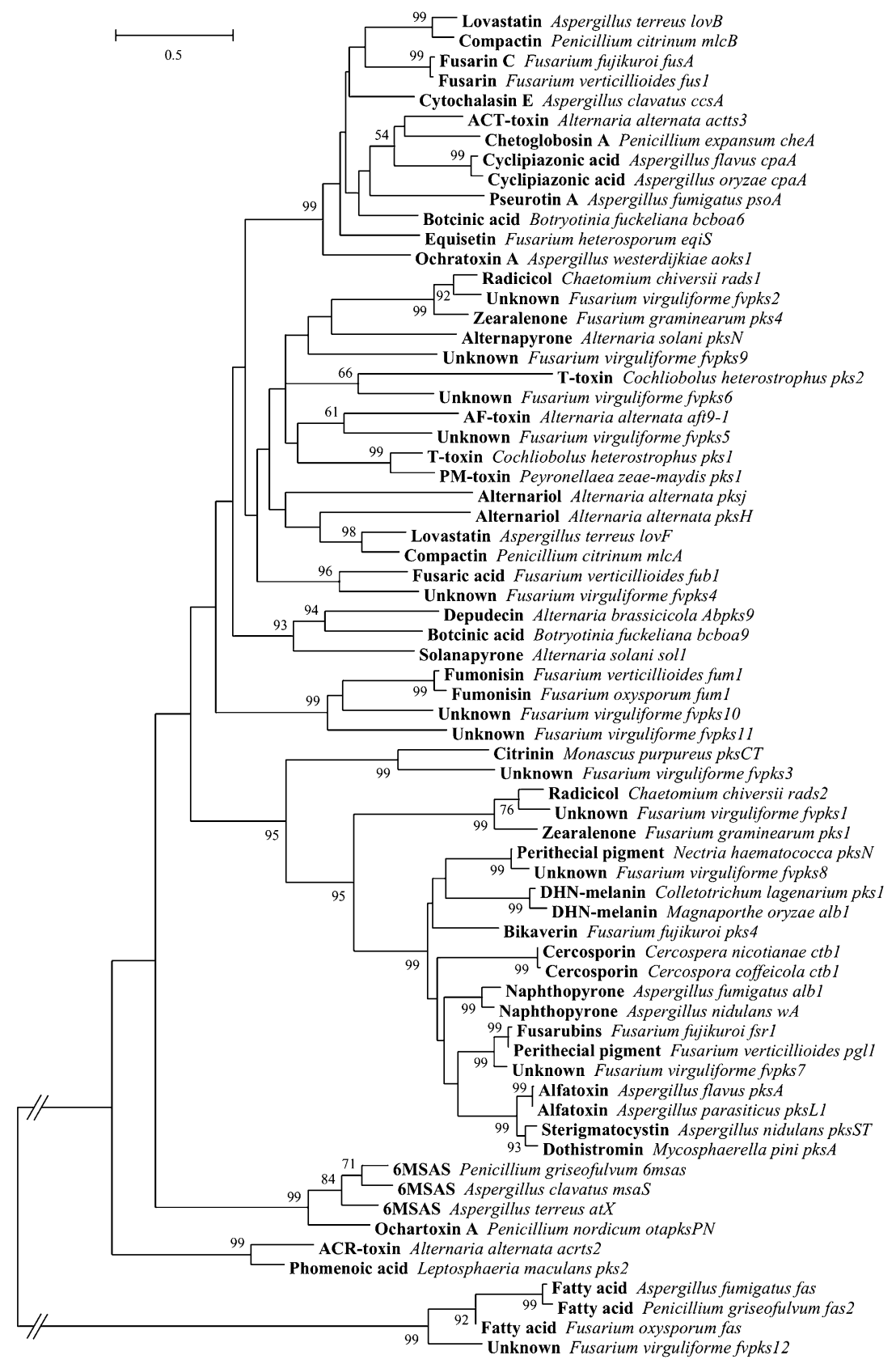

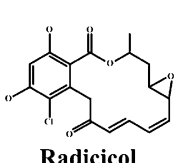
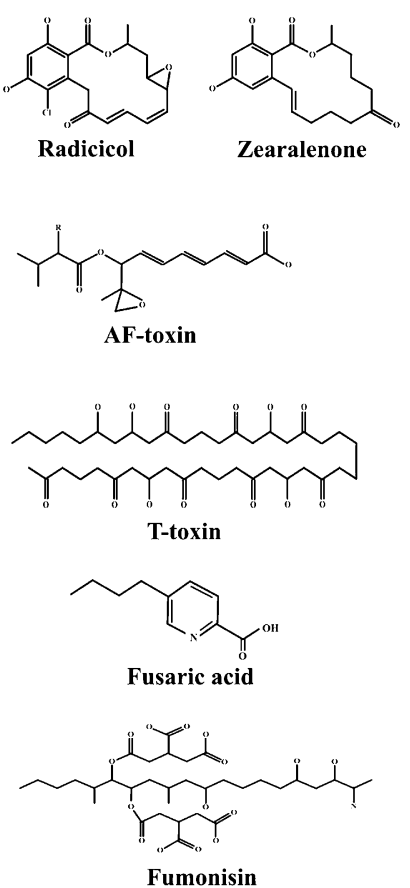

umonisin

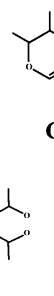<smiles>C=C(C)C1=CC2=C(C=CC1=C)C(C)CC2</smiles>

Citrinin

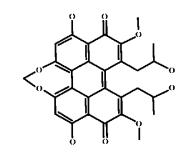

Cercosporin
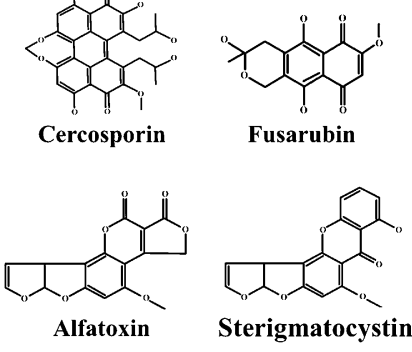

PR-PKS

Outgroup

Fig. 1. Phylogenetic analysis for polyketide synthases (PKS) of Fusarium virguliforme. The background database contains the KS domain protein sequence of fungal PKS, which was classified based on reduction potential: highly-reducing (HR), partially-reducing (PR), and nonreducing (NR). Six PKS of F. virguliforme had high similarity to PKS that synthesize citinin, fumonisin, fusaric acid, and radicicol. Bayesian information criterion: 64837.161; Akaike information criterion corrected: 63743.102; and maximum likelihood value: -31735.804 . Bootstrap support values below 50 were not shown at nodes. 
and soybean inoculated with SMV::FvTox 1 did not develop the extensive interveinal necrosis observed in soybean inoculated with SMV::FvNIS1 (Fig. 4A to D). The expression of SMV:: FvNIS1 did not fluctuate significantly from 20 to $40 \mathrm{dpi}$, which was similar to the empty SMV vector and the SMV:: FvTox1, based on qRT-PCR. This suggested that the acceleration in foliar severity was independent of SMV::FvNIS1 expression over time (Fig. 4E). To determine if the phytotoxicity induced by SMV::FvNIS1 was universal in different soybean genotypes, we inoculated 80 soybean plant introductions (PI) with SMV::FvNIS1. All PI except five were susceptible, displaying the classic symptoms of chlorosis and necrosis. Five PI (PI 548301, PI 567742B, PI 594399C, PI 603524, and PI 603581) did not display distinct necrosis, even though SMV mosaic symptoms were evident (Fig. 5A). While some PI, such as PI 408335A, PI 092713, and PI 634903, displayed less sensitivity to SMV::FvNIS1 compared with 'Essex' by showing necrotic spots that did not coalesce to interveinal necrosis within 40 dpi. Others, such as PI 567648C and PI 548459, displayed extreme sensitivity to SMV:FvNIS1 compared with 'Essex' by showing faster development of typical SDS foliar symptoms that could be observed around 20 to 25 dpi (Fig. 5A).
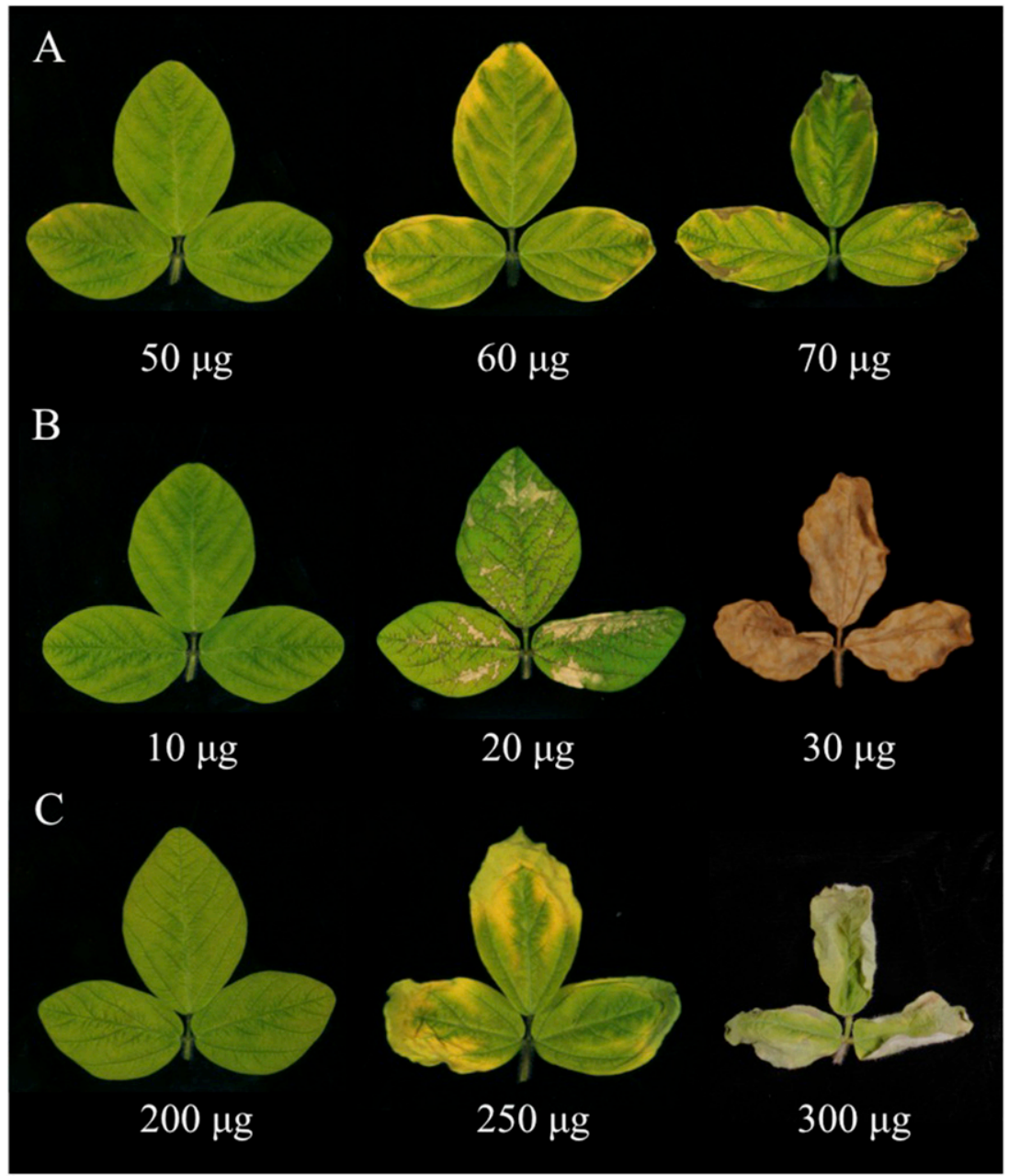

Fig. 2. Foliar symptoms induced by $\mathbf{A}$, citrinin, B, fusaric acid, and $\mathbf{C}$, radicicol at 3 days postinoculation.

Table 2. Identification of putative phytotoxic effectors

\begin{tabular}{|c|c|c|c|c|}
\hline Name & Gene ID & Gene size (bp) & Annotation & E value \\
\hline futoxl & g14460 & 519 & Fusarium virguliforme Tox 1 & $4 e-124$ \\
\hline fvtox 2 & g14684 & 369 & - & - \\
\hline fvcpl & g1821 & 666 & Nectria hematococca mpVI 77-13-4 Cerato-platanin & $1 e-152$ \\
\hline fvcp 2 & g9439 & 423 & Fusarium oxysporum f. sp. cubense race 4 SnodProt1 & $5 e-66$ \\
\hline fvсp3 & g8440 & 855 & Nectria hematococca mpVI 77-13-4 Cerato-platanin & $4 e-148$ \\
\hline fucdipl & g4207 & 1065 & $\begin{array}{l}\text { Magnaporthe oryzae } 70-15 \text { cell death-inducing } \\
\text { protein }\end{array}$ & $5 e-180$ \\
\hline fvnlpl & g5890 & 711 & $\begin{array}{l}\text { Nectria hematococca mpVI 77-13-4 NPP1 domain } \\
\text { protein }\end{array}$ & $3 e-144$ \\
\hline fvnlp2 & g8126 & 390 & $\begin{array}{l}\text { Nectria hematococca mpVI 77-13-4 NPP1 domain } \\
\text { protein }\end{array}$ & $6 e-82$ \\
\hline fvnlp3 & g2173 & 852 & Colletotrichum higginsianum NPP1 domain protein & $6 e-45$ \\
\hline fvnlp 4 & g3087 & 1203 & Trichoderma virens Gv29-8 NPP1 domain protein & 0.0 \\
\hline funisl & g13723 & 426 & Colletotrichum orbiculare NIS1 & $2 \mathrm{e}-66$ \\
\hline
\end{tabular}


Genome-wide association study (GWAS) to identify loci for sensitivity to SMV::FvNIS1.

The 80 soybean PI inoculated with SMV::FvNIS1 (Supplementary Table S3) were used to identify potential single nucleotide polymorphisms (SNPs) associated with the sensitivity to FvNIS1. All PI displayed some virus symptoms of mosaic, mild leaf chlorosis, or stunting but not systemic necrosis. The phenotype data collected was based on whether or not necrosis was induced after inoculating with SMV::FvNIS1. In accordance with the inverse gene-for-gene model, we hypothesized that a corresponding receptor might exist in susceptible soybean PI that recognize FvNIS1 and produce necrosis. Bayesian information criterion (BIC)-based model selection, principal component analysis (PCA), and a quantile-quantile (Q-Q) plot indicated negligible population structure and the appropriateness of the GWAS model (Fig. 5B and C; Supplementary Table S4). GWAS identified one and two significant SNPs located on chromosomes 6 and 20, respectively (Table 3). While locus1FvNIS1 (chromosome 20) passed the Bonferroni threshold with one LRR receptor-like protein kinase (RLK) gene near the SNPs, locus2-FvNIS1 (chromosome 6) had two candidate LRR-RLK genes nearby and the SNP located within QTL13-11 for SDS resistance (Abdelmajid et al. 2012; SoyBase and the Soybean Breeder's Toolbox website). The identification of these LRR-RLK genes raises the possibility that FvNIS1 might be recognized by one or more plant receptors in the apoplastic space, perhaps similar to the orthologous NIS1 of Colletotrichum orbiculare, which was shown to be an apoplastic effector (Irieda et al. 2014).

\section{Gene knockout analysis of FvNIS1.}

Since FvNIS1 produced symptoms that most closely resembled typical SDS foliar symptoms, $\Delta$ fvnis 1 knockout mutants were constructed using a split-marker approach. Because the three knockout mutants that we created displayed no phenotypic differences to each other, we subsequently generated two complementation strains by inserting the fvnis 1 gene back into fvnis1-1 knockout mutant (Supplementary Fig. S4). In brief, mutants and complementation strains displayed no differences compared with the wild type in colony morphology, growth rate, or sporulation. In addition, there was no appreciable difference in the expression of other candidate phytotoxin-related genes during infection, except for undetectable fvnis 1 expression in the $\Delta$ fvnis $1-1$ knockout mutant (Fig. 6A). These results indicated that fvnisl was not essential for survival or vegetative growth. Based on the stem-cutting assay, the culture filtrate produced by the $\Delta$ fvnis $1-1$ knockout mutant had reduced phytotoxicity causing milder symptoms with a lower $(P<0.05)$ area under disease progress curve (AUDPC) (Fig. 6B and C).

\section{DISCUSSION}

Phytotoxins of $F$. virguliforme translocated from soybean roots to leaves cause SDS foliar symptoms, as the fungus resides in the roots but not the stems or leaves of infected plants (Hartman et al. 2015). We hypothesized that multiple phytotoxins cause SDS foliar symptoms. We applied bioinformatics to identify additional phytotoxins produced by $F$. virguliforme and identified transcripts for the synthesis of citrinin, fusaric acid, radiciol, and 11 additional phytotoxic effectors.

Citrinin was first identified in Penicilliun citrinum and, later, was found in several Aspergillus and Monascus species (AbouZeid 2012). Our study is the first to show that a Fusarium species can synthesize citrinin. Citrinin interferes with several

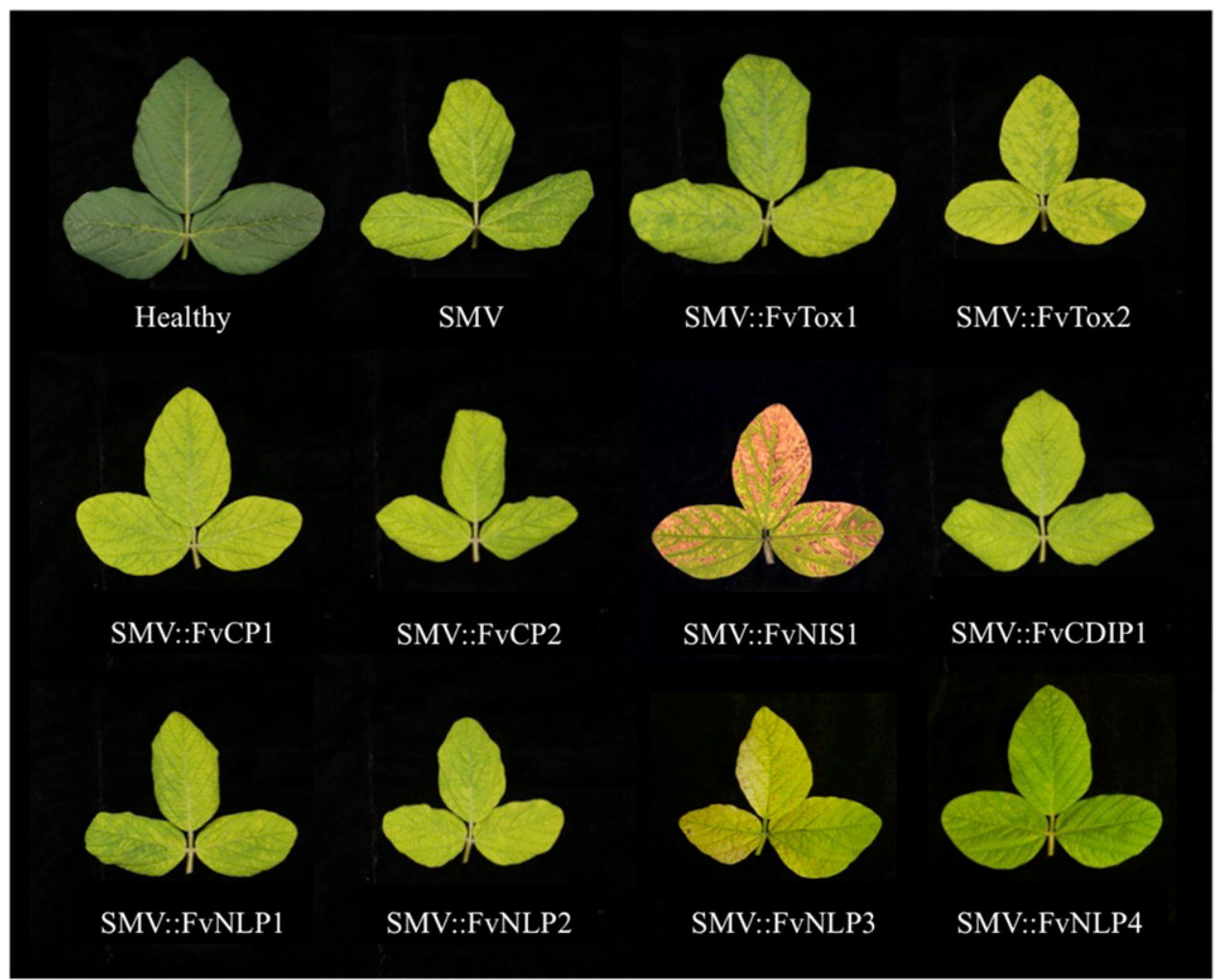

Fig. 3. Characterization of phytotoxic effectors using a Soybean mosaic virus (SMV) expression system. SMV expressing FvTox1, FvTox2, FvCP1-2, FvCDIP1, and FvNLP1 to FvNLP4 did not induce sudden death syndrome (SDS)-like foliar symptoms. Instead, SMV expressing FvNIS1 displayed typical SDS foliar symptoms, including interveinal chlorosis and necrosis and marginal upward curling of leaflets. Leaves with severe symptoms tended to defoliate easily as well. 
physiological processes, including the promotion of superoxide production (Ribeiro et al. 1997), interruption of ion redox cycle (Da Lozzo et al. 2002), and induction of cell cycle progression without DNA damage (Kuroda et al. 2013). A recent study reported that citrinin was not required for Penicillium expansum to infect apples (Ballester et al. 2015). Fusaric acid has been shown to induce wilting and necrosis of banana (Li et al. 2013). Radicicol inhibits heat shock protein 90, and its inactivation may allow parasitic fungi to establish infections (Piper and Millson 2012). It has also been hypothesized that radicicol released by $C$. graminicola may inhibit plant defense responses as well as suppress competing microbial communities in a symptomless mechanism (Wicklow et al. 2009). Citrinin, fusaric acid, and radicicol induced foliar chlorosis and wilting in our study, which differed from the typical interveinal chlorosis and necrosis commonly observed with SDS foliar symptoms.

In addition to polyketide phytotoxins, we identified 11 effectors that may be phytotoxic to soybean. Agrobacterium infiltration has been used in Arabidopsis and tobacco to test foliar symptoms induced by effectors in plants, but because of the difficulty of performing leaf infiltration in soybean (Vleeshouwers and Oliver 2014), we visualized phytotoxicity symptoms induced by $F$. virguliforme effectors by transiently expressing them individually via SMV. Overexpression FvTox1 via SMVinduced mild chlorosis on leaves, which is consistent with previous reports that leaves treated with purified FvTox1 showed mild chlorosis and a reduction of chlorophyll content on susceptible leaf disks (Brar et al. 2011). FvTox1 has been regarded as an important phytotoxin associated with SDS foliar symptoms because $\Delta$ fvtoxl knockout mutants had reduced phytotoxicity to soybean (Pudake et al. 2013). However, it was not reported whether the $\Delta$ fvtoxl mutants displayed equivalent phenotypic traits, such as sporulation, compared with the wild type isolate. In addition to FvTox1, the expression of the 17-kDa effector FvTox 2 was detected in our transcriptome based on the identity of the $\mathrm{N}$-terminal partial peptide sequence (Jin et al. 1996). However, overexpression of FvTox 2 exhibited mild chlorosis with few necrotic spots.
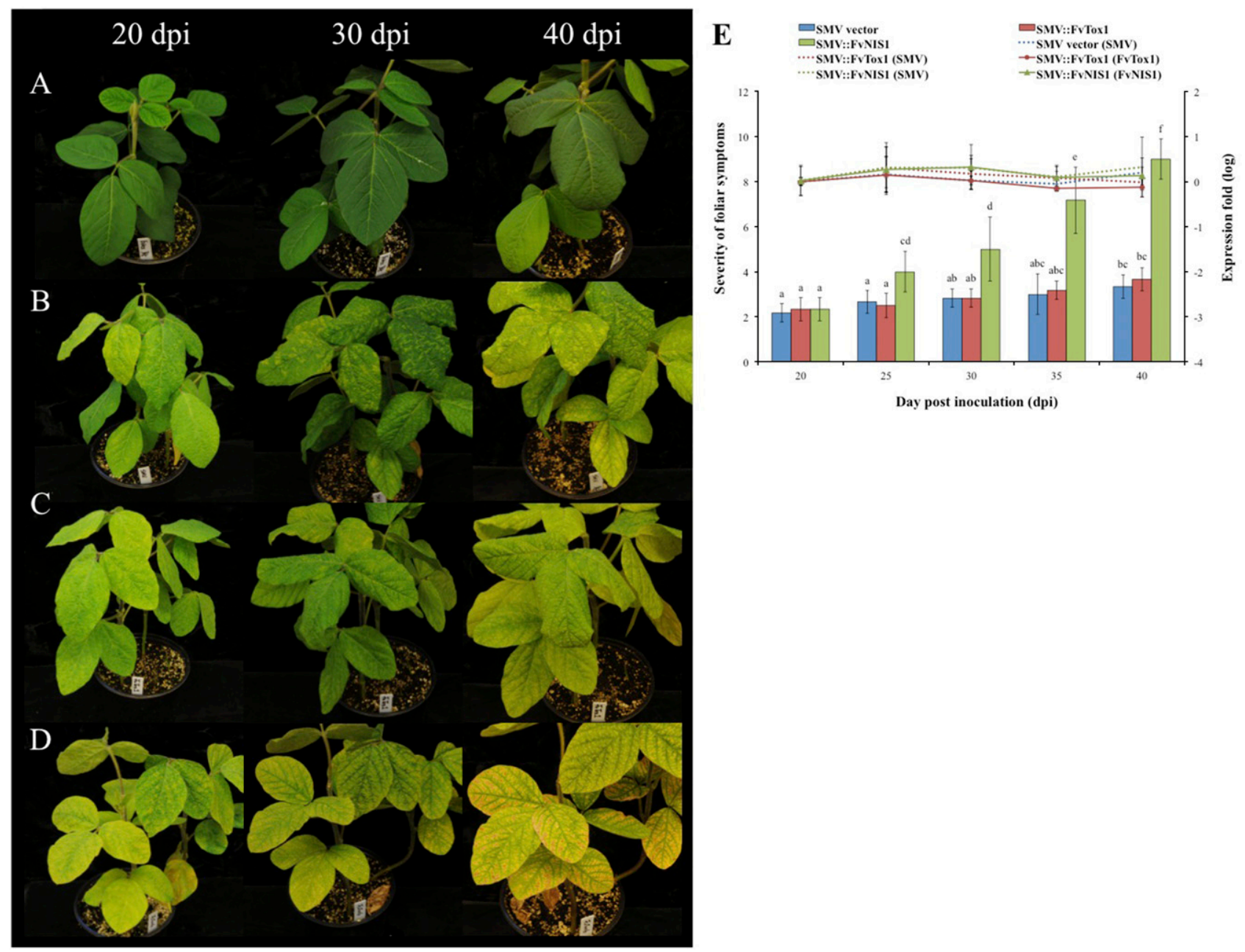

Fig. 4. Sudden appearance of sudden death syndrome (SDS)-like foliar symptoms induced by FvNIS1 over time. A, Healthy soybean cultivar Essex. B, Soybean inoculated with empty Soybean mosaic virus (SMV) vector, showing typical mosaic symptoms at 20 through 40 days postinoculation (dpi). C, Soybeans inoculated with SMV::FvTox1, visually indistinguishable to SMV vector. D, Soybeans inoculated with SMV::FvNIS1, displaying chlorotic spots that later turned into necrotic spots around $20 \mathrm{dpi}$, interveinal chlorosis around $30 \mathrm{dpi}$, and severe interveinal necrosis by $40 \mathrm{dpi}$. E, Quantification of viral expression and foliar severity in SMV-, SMV::FvTox1-, and SMV::FvNIS1-inoculated soybeans. The expression of SMV and fvtox1 in SMV::FvTox1inoculated plants and the expression of SMV and fvnis 1 in SMV::FvNIS1 inoculated plants were not significantly different from the expression of SMV in SMV-inoculated plants over time. However, the foliar severity of SMV::FvNIS1-inoculated plants increased significantly between 30 to 40 dpi. The results indicated the severity caused by SMV::FvNIS1 was not related to fvnisl expression in plants. Bar chart and left $y$ axis indicates the severity of SDS-like foliar symptoms. Line chart and right $y$ axis indicates the expression fold $\left(\log _{10}\right)$ normalized to 20 dpi for each group. Parentheses in the line legend indicate the target gene for quantitative reverse transcription-polymerase chain reaction detection. Significance was determined at $P<0.01$. 
A
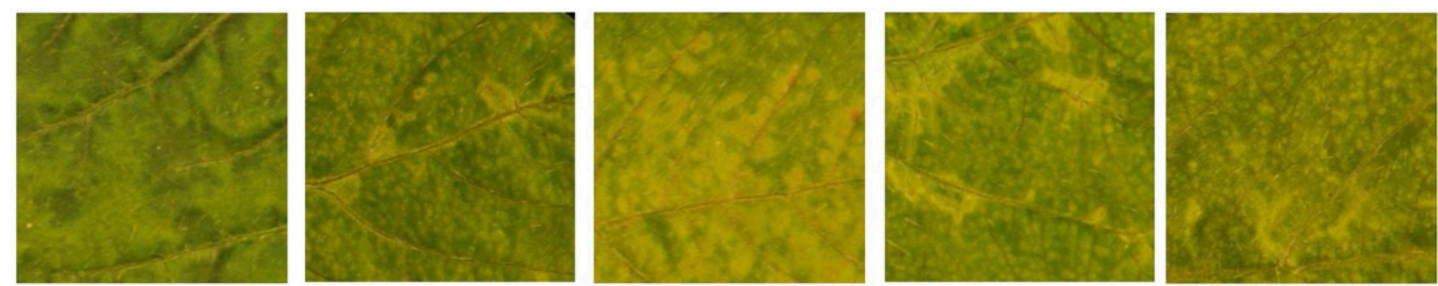

PI548301
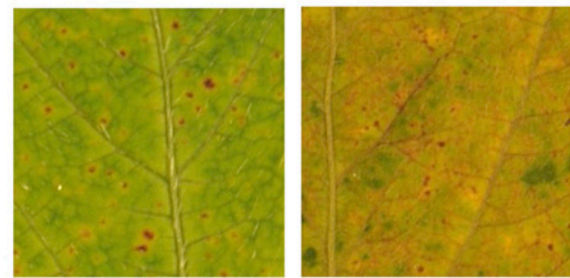

PI408355A

PI092713

B

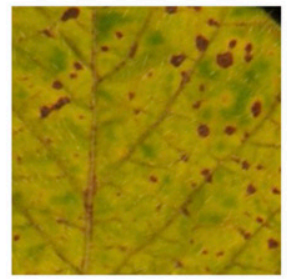

PI634903

PI603524

PI603581

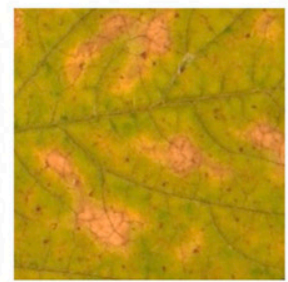

PI567648C

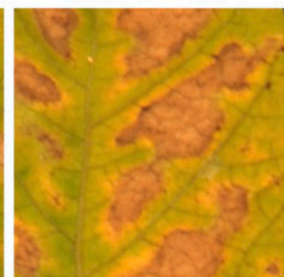

PI548459

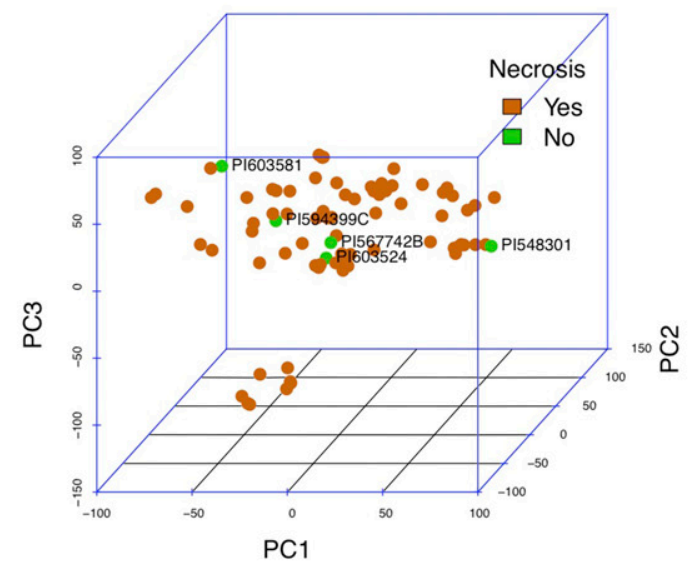

C

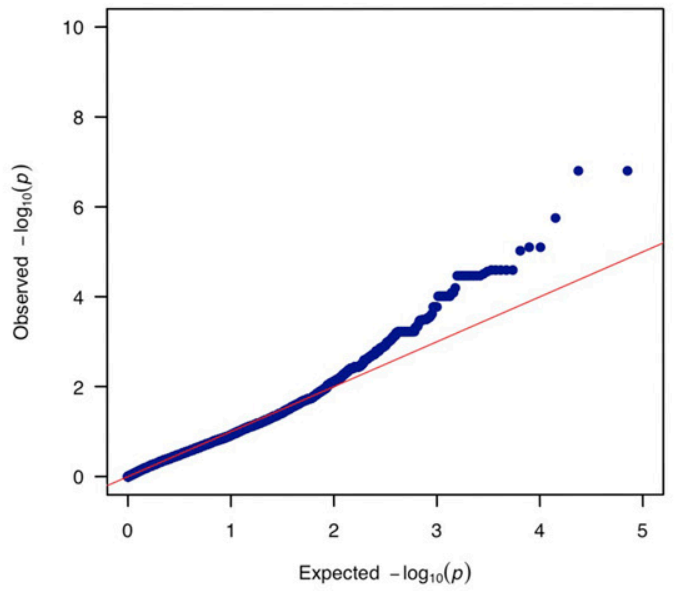

D

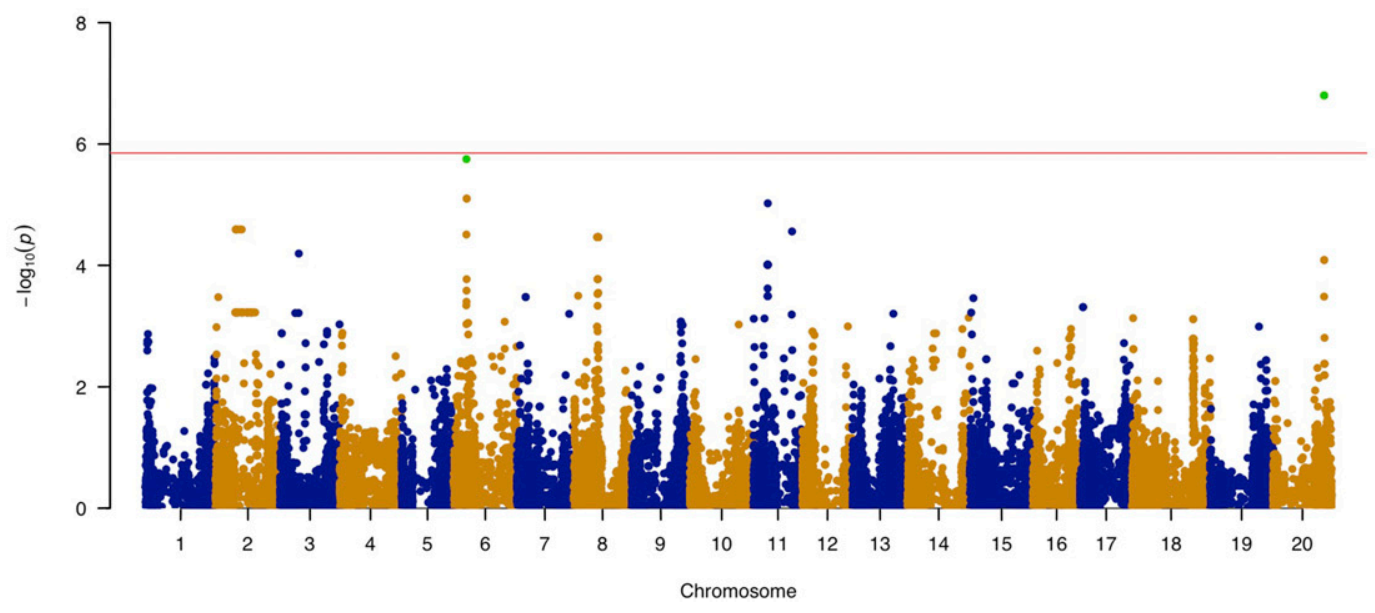

Fig. 5. Genome-wide association study (GWAS) to identify soybean loci associated with sensitivity to SMV::FvNIS1. A, SMV::FvNIS1 induced different intensities of leaf chlorosis and necrosis on 75 soybean genotypes but not PI 548301, PI 567742B, PI 594399C, PI 603524, and PI 603581. Resistant soybean genotypes that displayed mosaic or chlorotic spots were classified as 0 , while susceptible varieties that displayed necrotic spots to interveinal necrosis were classified as 1. B, A principal component analysis plot indicated negligible population structure in the 80 soybean varieties. C, A quantile-quantile plot indicated the appropriateness of the GWAS model. D, GWAS identified three single nucleotide polymorphisms (SNPs) with a false discovery rate $<0.05$ (shown in green). Two SNPs on chromosome 20 overlapped because of their close distance. The most significant locus, FvNIS1, exceeded the Bonferroni threshold and had not been reported to associate with sudden death syndrome. The second, locus2-FvNIS1, has significance just below the Bonferroni threshold and was located within the region of a reported quantitative trait locus, SDS13-11. 
The FvCP1-3 belongs to the cerato-platanin family, which has been found in several plant-pathogenic fungi as an important virulence factor (Frías et al. 2014) involved in triggering plant defense responses and inducing accumulation of reactive oxygen species (Baccelli et al. 2014; Frías et al. 2013). However, the roles of cerato-platanin proteins vary. For example, the cerato-platanin Sp1 of Leptoshaeria maculans was not able to induce necrosis and the deletion mutant did not reduce virulence (Wilson et al. 2002), whereas the cerato-platanin MgSM1 of $M$. grisea induced necrosis and triggered defense responses in Arabidopsis (Yang et al. 2009) and the targeted gene-deletion mutant compromised pathogenicity (Jeong et al. 2007). Cerato-platanin BcSpl1 of Botrytis cinerea was regarded as a phytotoxic effector that caused electrolyte leakage and cytoplasmic shrinkage (Frías et al. 2011). In our phytotoxicity tests, SMV::FvCP1 and SMV::FvCP2 did not display SDS-like foliar symptoms, although FvCP2 has been isolated from the xylem sap of $F$. virguliforme-infected seedlings (Abeysekara and Bhattacharyya 2014). In addition to cerato-platanin, we identified a putative secretory protein, FvCDIP1, that is orthologous to MoCDIP1. MoCDIP1 is one of the cell death-inducing proteins of $M$. oryzae. MoCDIP1 was expressed at the late infection stage and caused necrosis in both dicots and monocots (Chen et al. 2013). In our study, FvCDIP1 did not induce obvious SDS-like foliar symptoms.

The first NLP was identified from the culture filtrate of plant-pathogenic $F$. oxysporum, and orthologous NLP have been found in prokaryotes, oomycetes, and many other fungi (Oome and Van den Ackerveken 2014). Plant-associated fungi or oomycetes generally harbor multiple NLP and these homologs could be functionally redundant (Santhanam et al. 2013; Zhou et al. 2012). It has been suggested that NLP cause the release of damage-associated molecular patterns that trigger plant defense responses through different signaling cascades, rather than acting themselves as elicitors for plant defense responses (Kanneganti et al. 2006; Kleemann et al. 2012). Studies have shown that hemibiotrophic pathogens secrete NLP-suppressing effectors at the early biotrophic stage of infection, to avoid NLP phytotoxicity (Kelley et al. 2010; Kleemann et al. 2012). Moreover, NLP were regarded as phytotoxins because of their necrosis-inducing activity (Schouten et al. 2008) and because NLP genes were generally up-regulated when hemibiotrophic pathogens switch from biotrophic to necrotrophic stages (Qutob et al. 2002). While transient expression of many NLP induce necrosis, some NLP were nonphytotoxic (Cabral et al. 2012; Dong et al. 2012; Feng et al. 2014; Santhanam et al. 2013). Eleven conserved amino acids were shown to induce necrosis with disulfide bond-forming cysteine residues being essential (Oome and Van den Ackerveken 2014). Substitutions in these conserved amino acids may eliminate phytotoxicity. A nonphytotoxic NLP of Colletotrichum spp. with substitutions in the conserved heptapeptide GHRHDWE was reported to be the reason for the loss of the necrosis-inducing function (Kleemann et al. 2012; Oome and Van den Ackerveken 2014). In the case of $F$. virguliforme, we did not observe SDS-like foliar symptoms by overexpressing FvNLP1 to FvNLP4 via SMV. We noticed that FvNLP1-3 all had a substitution within the heptapeptide region while FvNLP4 contained two substitutions in other conserved residues (Supplementary Fig. S5). It is not known if these substitutions affected the necrosis-inducing capability of FvNLP1 to FvNLP4.

We discovered FvNIS1 independently induced SDS foliar symptoms similar to field-observed SDS foliar symptoms when overexpressing FvNIS1 through a SMV-mediated transient system. FvNIS1 is an orthologous protein to the $C$. obiculare secretory protein NIS1 (Yoshino et al. 2012). NIS1 was isolated from culture filtrate of $C$. obiculare, and it induced necrosis in tobacco leaves by Agrobacterium tumefaciens-mediated transient expression. Furthermore, nis 1 was not required for the pathogenicity of $C$. obiculare and it was suggested that NIS1 may induce cell death via a corresponding receptor in plants or act as a phytotoxin (Yoshino et al. 2012). Our study showed the development of SDS foliar symptoms was not dependent on the expression level of funis 1 and the phytotoxicity mimicked the development of SDS foliar symptoms in the field. Although transient overexpression of most effectors identified in this study failed to induce foliar symptoms, qRT-PCR revealed their activities during infection; and because phylogenetic analyses did not provide insightful information for several PKS and most NRPS of F. virguliforme, it is still possible that other secondary metabolites and effectors may be involved in producing SDS foliar symptoms.

In this study, we successfully applied bioinformatics to identify phytotoxins produced by $F$. virguliforme. All previously reported phytotoxins were again found using this methodology, including radicicol, FvTox1, and FvTox2, which demonstrated the inclusiveness of this approach. Because FvNIS1 displayed selective phytotoxicity on soybean genotypes, we applied GWAS and identified two loci in soybean that corresponded to the symptoms induced by overexpressing FvNIS1. Although $\Delta$ fvnisl knockout mutants only slightly reduced phytotoxicity to soybean leaves, the identification of FvNIS1 and its corresponding loci in soybean increases our understanding of how the effector might interact with soybean. Indeed, the contributions of phytotoxic effectors have been shown to vary in pathosystems. For example, while Ptr ToxA of Pyrenophora tritici-repentis plays a dominant role in virulence (Moffat et al. 2014), SnToxA, SnTox1, and SnTox3 individually have a lesser effect while even triple knockout mutants of these three effectors still induced foliar symptoms (Tan et al. 2015). Nevertheless, studies on phytotoxic effectors of Parastagonospora nodorum to their corresponding QTL in wheat have been used in wheat breeding even though studies on the individual effector may not appear to be impactful (Tan et al. 2015; Vleeshouwers and Oliver 2014). Future studies focusing on understanding the phytotoxicity mechanism of FvNIS1 may elucidate why FvNIS1 required 30 to 40 days to display typical SDS foliar symptoms even though the gene expression was detected as early as $20 \mathrm{dpi}$. Cloning of

Table 3. Significant single nucleotide polymorphisms, loci, and candidate leucine-rich repeat-receptor-like protein kinase genes in the genome-wide association study model

\begin{tabular}{|c|c|c|c|c|c|c|c|c|}
\hline Loci & ss_id & Chrm & Position & $\mathbf{M A F}^{\mathbf{a}}$ & $P$ value & FDR $^{\mathbf{a}}$ & Overlapped $\mathbf{Q T L}^{\mathrm{a}}$ & Candidate genes \\
\hline locus1-FvNIS1 & ss715638194 & 20 & $40,656,371$ & 0.05 & $1.58 \mathrm{E}-07$ & 0.003 & - & Glyma.20g 181100 \\
\hline & ss715638215 & 20 & $40,809,306$ & 0.05 & $1.58 \mathrm{E}-07$ & 0.003 & - & \\
\hline locus2-FvNIS1 & ss715592683 & 6 & $10,231,292$ & 0.10 & $1.77 \mathrm{E}-06$ & 0.021 & SDS13-11 & $\begin{array}{l}\text { Glyma.06g } 124200 \\
\text { Glyma.06g124700 }\end{array}$ \\
\hline
\end{tabular}

${ }^{\mathrm{a}} \mathrm{MAF}=$ minor allele frequency; FDR = false discovery rate; and QTL = quantitative trait locus. 
putative FvNIS1-interacting LRR-RLK genes may provide insights about how FvNIS1 induces necrosis and foliar symptoms in susceptible soybean PI.

\section{MATERIALS AND METHODS}

\section{Preparation of in vitro transcriptome from mycelia} and the stem-cutting assay.

Fusarium virguliforme Mont-1 was maintained on potato dextrose agar (PDA) (Difco, Sparks, MD, U.S.A.) at $25^{\circ} \mathrm{C}$. Five PDA blocks (6 $\mathrm{mm}$ in diameter) from the distal part of the colony were transferred into $50 \mathrm{ml}$ of soybean dextrose broth (SDB) in $250-\mathrm{ml}$ flasks and were incubated at $25^{\circ} \mathrm{C}$ in the dark on an orbital shaker at $100 \mathrm{rpm}$. Mycelial blocks were homogenized after 2 days and were reincubated for 1 day in the original SDB. Five milliliters of mycelial suspension (mycelia dry weight averaged $14.6 \pm 1.0 \mathrm{mg}$ per $\mathrm{ml}$ ) was transferred into $50 \mathrm{ml}$ of new SDB and was cultured at $25^{\circ} \mathrm{C}$ in the dark without shaking. Mycelia and culture filtrates were harvested after 5 and 20 days of incubation. Mycelia were separated using Whatman \#1 filter paper (Fisher Scientific, Pittsburgh, PA, U.S.A.), were immediately frozen in liquid nitrogen in 15-ml polypropylene tubes (Corning, Corning, NY, U.S.A.), and were lyophilized and stored at $-80^{\circ} \mathrm{C}$. Culture filtrates were filtered through a $0.22-\mu \mathrm{m}$ filter (EMD Millipore, Billerica, MA, U.S.A.) and were stored at $4{ }^{\circ} \mathrm{C}$. SDS-susceptible soybean cultivar Essex plants were grown in a growth chamber at $30^{\circ} \mathrm{C}$, and at the $\mathrm{V} 1$ growth stage, a stem-cutting assay was used for testing the phytotoxicity of the culture filtrate. Stems of cut soybean plants were immersed in 50-ml polypropylene tubes $(2 \mathrm{ml}$ of culture filtrate per $50 \mathrm{ml})$. After observing foliar SDS symptoms (Supplementary Fig. S6), total RNA was extracted from the lyophilized mycelia using a homogenizer (MP Biomedicals FastPrep-24, Santa Ana, CA, U.S.A.) and TRIzol reagent (Life Technologies, Carlsbad, CA, U.S.A.). RNA was treated with DNase (New England BioLabs, Ipswich, MA, U.S.A.) and the quality was determined by a Bioanalyzer (Agilent Technologies, Santa Clara, CA, U.S.A.). Six RNA-Seq libraries (three biological replications of two time points) were individually barcoded and prepared by TruSeq Stranded RNAseq Sample Prep kit (Illumina, San Diego, CA, U.S.A.). The pooled libraries were sequenced on one lane for 100 cycles (single read) on a HiSeq2000 at the Roy J. Carver Biotechnology Center, University of Illinois (Urbana, IL, U.S.A.), using TruSeq SBS sequencing kit version 3 according to the manufacturers' protocols.

\section{Transcriptome analysis.}

Raw Illumina sequence reads of the six samples were filtered using the FASTX toolkit (version 0.0.13) to remove reads that failed to meet a minimum quality score of 28 and minimum length of 90 nucleotides. Tophat2 (version 2.0.10) (Kim et al. 2013) was applied in default mode with the F. virguliforme Mont-1 genome and annotation as reference
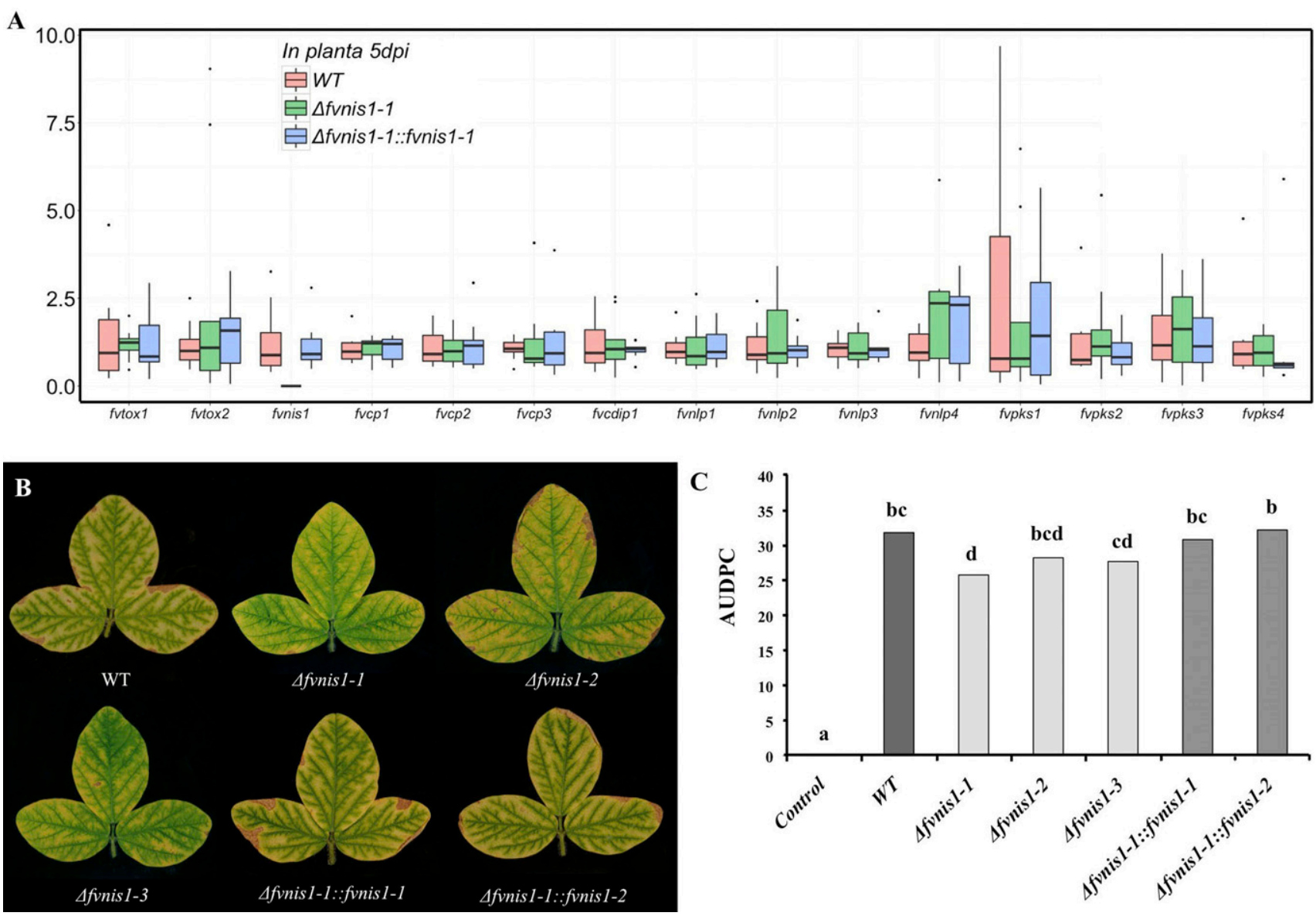

Fig. 6. $\Delta$ funis 1 mutants maintained phytotoxicity on soybean leaves. A, Fusarium virguliforme wild type (WT), $\Delta$ funis 1 mutants, and funis 1 complementation strains exhibited similar expression levels on genes that encode polyketide synthases and other phytotoxic effectors other than FvNIS1. The results indicated target gene replacement of fvnis 1 did not affect other phenotypes. B, Culture filtrates of $\Delta$ fvnis 1 mutants displayed reduced phytotoxicity but still caused interveinal chlorosis and some necrosis. C, Quantification of the culture filtrate phytotoxicity through a stem-cutting assay over 7 days. The area under disease progress curve was used to represent phytotoxicity of WT, $\Delta$ fvnis 1 mutants, and fvnis 1 complementation strains. 
(Srivastava et al. 2014). The transcripts of the six samples were assembled by Cufflinks (version 2.2.1) and transcriptomes merged by Cuffmerge (Kim et al. 2013; Trapnell et al. 2012). HTSeq (version 0.6.1) (Anders et al. 2014) was used to count the mapped reads for each transcript. Those transcripts with less than 60 reads across six libraries were filtered out. Augustus was used to predict putative proteins in the genome and transcriptome with $F$. graminearum as a model organism. Default parameters were used except for the minexonintronprob $(=0.1)$ and the minmeanexonintronprob $(=0.4)$ (Keller et al. 2011). HMMER version 3.0 (Finn et al. 2011) was applied to search KS (pfam ID: PF00109 and PF02801) and AT domains (PF00698) for PKS, A (PF00501) and C domains (PF00668) for NRPS, and TRI5 (PF06330) for trichodiene synthase. Genes that contained at least one KS domain and one AT domain were regarded as PKS genes. Genes that contained at least one A domain and one $\mathrm{C}$ domain were regarded as NRPS genes. SignalP (version 4.1) was used to predict proteins with secretory peptides but not the transmembrane region (Petersen et al. 2011). Annotation and protein domain prediction was further analyzed by BLASTP and hmmsearch.

\section{Identification and characterization \\ of phytotoxic secondary metabolites.}

The $\mathrm{N}$ terminal and $\mathrm{C}$ terminal of PKS amino acid sequences were concatenated to represent one PKS. For NRPS, the protein sequences of A domains were identified as separate inputs (Gallo et al. 2013). Protein sequence alignments were conducted by MUSCLE and maximum-likelihood trees with 1,000 bootstrap replicates were constructed by MEGA6 (version 6.0.6) (Tamura et al. 2013), using the $\mathrm{LG}+\mathrm{G}+\mathrm{I}$ and $\mathrm{rtREV}+\mathrm{G}+\mathrm{F}$ models for PKS and NRPS, respectively.

Five-milliliter cell-free culture filtrates were serially treated with $5 \mathrm{ml}$ each of acetonitrile (Fisher Scientific), chloroform (MP Biomedicals), and ethyl acetate (Fisher Scientific) for $5 \mathrm{~min}$ each, while shaking. Solvents were separated by centrifugation at $4,000 \mathrm{rpm}$ for $5 \mathrm{~min}$. The organic layers were transferred into 2-ml tubes and were air-dried at room temperature overnight. Dried samples were kept at $-20^{\circ} \mathrm{C}$ and were dissolved into $85 \%$ methanol before analyses. Samples were analyzed with the 5500 QTRAP LC/MS/MS system (AB Sciex, Framingham, MA, U.S.A.) with a 1200 series HPLC system (Agilent Technologies) at the Roy J. Carver Biotechnology Center. The LC separation was performed on an Agilent SB-Aq column $(4.6 \times 50 \mathrm{~mm}, 5 \mu \mathrm{m})$ (Agilent Technologies) with mobile phase A (10 $\mathrm{mM}$ ammonia formate in water) and mobile phase $\mathrm{B}$ (methanol). The flow rate was $0.35 \mathrm{ml} / \mathrm{min}$. The linear gradient was: 0 to $1 \mathrm{~min}, 98 \% \mathrm{~A} ; 8$ to $13 \mathrm{~min}, 0 \% \mathrm{~A}$; and 13.5 to $19 \mathrm{~min}, 98 \% \mathrm{~A}$. The autosampler was set at $5^{\circ} \mathrm{C}$. The injection volume was $5 \mu$ l. Mass spectra were acquired with negative electrospray ionization at an ion spray voltage of $-4,500 \mathrm{~V}$. The source temperature was $450^{\circ} \mathrm{C}$. The curtain gas, ion source gas 1 , and ion source gas 2 were 248 , 345 , and $448 \mathrm{kPa}$, respectively. Multiple reaction monitoring was used to quantify target compounds: citrinin (AdipoGen, San Diego, CA, U.S.A.) m/z 249.0 to $\mathrm{m} / \mathrm{z}$ 177.1; fumonisin B1 (Cayman Chemical, Ann Arbor, MI, U.S.A.) $\mathrm{m} / \mathrm{z} 720.4$ to $\mathrm{m} / \mathrm{z} 157.0$; fusaric acid (ACROS Organics, Geel, Belgium) m/z 178.0 to $\mathrm{m} / \mathrm{z}$ 134.0; and radicicol (AdipoGen) m/z 363.1 to $\mathrm{m} / \mathrm{z} 275.0$. For the phytotoxicity assay, each compound was adjusted to the desired concentration and was dissolved in $1 \mathrm{ml}$ of water. Stem cuttings of soybean cultivar Essex at growth stage V1 were immersed in $1 \mathrm{ml}$ of solution in 50-ml polypropylene tubes for $3 \mathrm{~h}$. After $3 \mathrm{~h}, 50 \mathrm{ml}$ of water was added. The stem cuttings were incubated as previously described. After 3 days, foliar symptoms were observed and photographed.
Effector cloning and transit expression in soybean through particle bombardment.

Mycelia 1 cDNA was synthesized from total RNA by ProtoScript First Strand cDNA synthesis kit (New England BioLabs). The coding sequence of each putative phytotoxic effector-encoding gene was amplified from mycelial cDNA pools with primers (Supplementary Table S5). Each gene was cleaved with ClaI (or BstBI) and NheI and was ligated into pBR-SMV413 cut with the same restriction enzymes to produce SMV::Fv plasmids. Ligated plasmids were transformed into Turbo Competent Escherichia coli (New England BioLabs) and were selected by kanamycin (Fisher Scientific). Plasmid DNA was extracted by Qiagen spin miniprep kit (Qiagen, Valencia, CA, U.S.A.) and inserted sequences of plasmids were confirmed through BigDye Terminator Sequencing (Life Technologies) at the Roy J. Carver Biotechnology Center. SMV::Fv plasmid DNA for each putative phytotoxin gene $(50 \mu \mathrm{g})$ was precipitated onto $1.6-\mu \mathrm{m}$ gold microcarriers. Gold microcarriers were delivered into unifoliolate leaves of 10-day-old soybeans by the Helios gene gun system (Bio-Rad, Hercules, CA, U.S.A.). Inoculated soybeans were covered with plastic bags in the dark overnight before moving into growth chambers. Total RNA of inoculated soybeans was extracted at the second trifoliate. RT-PCR and Sanger sequencing were performed to check the stability of inserted genes. Leaf sap from gene gun-inoculated soybean plants was used to mechanically inoculate the unifoliolate leaves of 10-day-old soybeans using Carborundum as an abrasive, and the symptoms and stability of inserted sequences were confirmed again.

\section{Quantification of SMV expression by qRT-PCR and foliar symptom severity evaluation.}

Total RNA was extracted by TRIzol at 20, 25, 30, 35, and 40 dpi from leaves of soybeans that were inoculated with SMV, SMV::FvTox1, or SMV::FvNIS1. Random primers were used to synthesize total cDNA. Amplification efficiency of each pair of primers for qRT-PCR was determined based on four replicates and each replicate contained three concentration gradients (Supplementary Table S6). Platinum SYBR green qPCR SuperMix-UDG kit (Life Technologies) and Agilent Mx3005P qPCR System (Agilent Technologies) were used for qRT-PCR experiments. A cutoff threshold of 0.1 was used for cycle threshold $(\mathrm{Ct})$ determination. The $-\Delta \Delta \mathrm{Ct}$ method (Schmittgen and Livak 2008) was used to compare the expression of each gene to a reference gene, the soybean translation elongation factor 1B (Ma et al. 2013; Zhou et al. 2014). Relative expression analysis was normalized to $20 \mathrm{dpi}$. Evaluation of SMV and phytotoxin genes that inserted in SMV vector was repeated three times with two replicates per repeat. Total measurements were pooled $(n=150)$ and were analyzed by SAS in the proc mixed model by using three factors: gene, dpi, and gene:dpi combination. Repeats and replicates within each repeat were assigned as random factors. The slopes of each treatment were compared with the slope of SMV empty vector. Severity of foliar symptoms was graded. Total measurements $(n=90)$ were pooled for GLM analysis in $\mathrm{R}$.

\section{GWAS identification of soybean loci for SMV::FvNIS1 sensitivity.}

A total of 80 soybean PI requested from the United Stated Department of Agriculture soybean germplasm collection were evaluated for sensitivity to SMV::FvNIS1. Phenotypes were assigned into binary outcomes such that 0 represents mosaic symptoms without necrosis and 1 represents mosaic 
symptoms with necrosis. Genotypes of these soybean PI were extracted from SoySNP50K (Song et al. 2013). Missing SNPs were imputed by BEAGLE version 3.3.2 (Browning and Browning 2009). BIC-based model selection and PCA were used to evaluate population structure. Zero principal components were assigned in the GWAS model. SNPs with minor allele frequency below 0.05 were excluded, leaving 35,503 SNPs for GWAS. Significant SNPs were identified by GAPIT, using the MLM model (Lipka et al. 2012), and PLINK, using the Cochran-Armitage trend test model (Purcell et al. 2007). A $200-\mathrm{Mb}$ region that harbors the significant SNPs in the center was further extracted for Fisher's exact test to confirm the associations. A cutoff false discovery rate of 0.05 and Bonferroni-corrected threshold of $1.41^{-06}(P$ value of 0.05 over 35,503 independent tests) were used for determining significant SNPs.

\section{Construction of $\Delta$ fvnis 1 deletion mutants and complementation strains.}

A split-marker approach was used to generate fvnis $1 \mathrm{mu}-$ tants (Suppplementary Table S7). The TrpC promoter-driven hygromycin gene was cloned in between fvnisl upstream and downstream sequence. Upstream and downstream split markers were amplified by PCR and were delivered into protoplasts of $F$. virguliforme, following previous reported protocols (Ge et al. 2013; Mansouri et al. 2009; Szewczyk et al. 2006). Transformants were selected on PDA containing $30 \mu \mathrm{g}$ of hygromycin per milliliter. Single-spore isolation was conducted to acquire purified mutants that were grown on PDA containing $30 \mu \mathrm{g}$ of hygromycin per milliliter. To construct complementation strains, cDNA of FvNIS1 was cloned under TrpC promoter, and concatenated after a TrpC promoterdriven G418 resistant cassette. The complementation DNA sequence was delivered into protoplasts of $\Delta$ funis 1-1, using the same approach described above, and was then purified on PDA containing $50 \mu \mathrm{g}$ of G418 per milliliter. Mycelia 1 morphology, growth rate, sporulation, and in planta expression of other phytotoxin-related genes were evaluated to examine any physiological malfunction. Roots of soybean seedlings were germinated for 5 days at $25^{\circ} \mathrm{C}$. Each radicle was inoculated with $50 \mu \mathrm{l}$ of $1 \times 10^{6}$ macroconidia per milliliter of $F$. virguliforme. The conidia were collected from a 5-day-old culture grown on PDA. Inoculated radicles were incubated without light at $25^{\circ} \mathrm{C}$, and total RNA was extracted by TRIzol at 5 dpi. cDNA synthesis and qRT-PCR were conducted as described previously. Gene expression was normalized to the translation elongation factor 1A of $F$. virguliforme (FvEF1A) (Kim and Yun 2011). In planta gene expression analysis was repeated three times with three replicates for each. To understand whether fvnis 1 mutants had reduced phytotoxicity to soybean leaves, 20day-old SDB culture filtrates of wild-type Mont1, three $\Delta$ fvnis 1 mutants, and two $\Delta$ fvnis 1-1::fvnis 1 complementation strains were tested through a stem-cutting assay. Foliar severity was graded daily until $7 \mathrm{dpi}$, and AUDPC was calculated to represent the phytotoxicity of culture filtrates. The experiment was repeated four times with three replicates in each repeat for each strain. Total measurements $(n=84)$ were pooled for GLM analysis in R.

\section{ACKNOWLEDGMENTS}

We thank N. E. McCoppin for development of the SMV expression vector. We would also like to thank C. R. Bowen, J. S. Haudenshield, J.-H. Lee, S.-Y. L. Marzano, and Y. F. Zhao for their feedback on this study and A. E. Lipka for his assistance with the GWAS analysis. The North Central Soybean Research Program and the United States Department of Agriculture-Agricultural Research Service partially funded this project.

\section{LITERATURE CITED}

Abdelmajid, K. M., Ramos, L., Leandro, L., Mbofung, G., Hyten, D. L., Kantartzi, S. K., Grier, R. L., IV, Njiti, V. N., Cianzio, S., and Meksem, K. 2012. The 'PI 438489B' by 'Hamilton' SNP-based genetic linkage map of soybean [Glycine max (L.) Merr.] identified quantitative trait loci that underlie seedling SDS resistance. J. Plant Genomic Sci. 1:18-30.

Abeysekara, N. S., and Bhattacharyya, M. K. 2014. Analyses of the xylem sap proteomes identified candidate Fusarium virguliforme proteinacious toxins. PLoS One 9:e93667. doi:10.1371/journal.pone.0093667.

Abeysekara, N. S., Faris, J. D., Chao, S., McClean, P. E., and Friesen, T. L. 2012. Whole-genome QTL analysis of Stagonospora nodorum blotch resistance and validation of the SnTox4-Snn4 interaction in hexaploid wheat. Phytopathology 102:94-104.

Abou-Zeid, A. M. 2012. Review on citrinin: Synthetic methods, molecular biosynthesis and effect of plant extracts. Br. Microbiol. Res. J. 2:108-122.

Anders, S., Theodor, P., and Huber, W. 2014. HTSeq-A Python framework to work with high-throughput sequencing data. Published online: //biorxiv. org. BioRxiv, Cold Spring Harbor Laboratory, Cold Spring Harbor, NY, U.S.A.

Aoki, T., O’Donnell, K., Homma, Y., and Lattanzi, A. R. 2003. Suddendeath syndrome of soybean is caused by two morphologically and phylogenetically distinct species within the Fusarium solani species complex $-F$. virguliforme in North America and $F$. tucumaniae in South America. Mycologia 95:660-684.

Baccelli, I., Lombardi, L., Luti, S., Bernardi, R., Picciarelli, P., Scala, A. and Pazzagli, L. 2014. Cerato-platanin induces resistance in Arabidopsis leaves through stomatal perception, overexpression of salicylic acid- and ethylene-signalling genes and camalexin biosynthesis. PLoS One 9: e100959. doi:10.1371/journal.pone.0100959.

Baker, R. A., and Nemec, S. 1994. Soybean sudden death syndrome: Isolation and identification of a new phytotoxin from cultures of the causal agent, Fusarium solani. Phytopathology 84:1144.

Ballester, A.-R., Marcet-Houben, M., Levin, E., Sela, N., Selma-Lázaro, C., Carmona, L., Wisniewski, M., Droby, S., González-Candelas, L., and Gabaldón, T. 2015. Genome, transcriptome, and functional analyses of Penicillium expansum provide new insights into secondary metabolism and pathogenicity. Mol. Plant-Microbe Interact. 28:232-248.

Berestetskiy, A. 2008. A review of fungal phytotoxins: From basic studies to practical use. Appl. Biochem. Microbiol. 44:453-465.

Brar, H. K., Swaminathan, S., and Bhattacharyya, M. K. 2011. The Fusarium virguliforme toxin FvTox1 causes foliar sudden death syndrome-like symptoms in soybean. Mol. Plant-Microbe Interact. 24:1179-1188

Browning, B. L., and Browning, S. R. 2009. A unified approach to genotype imputation and haplotype-phase inference for large data sets of trios and unrelated individuals. Am. J. Hum. Genet. 84:210-223.

Cabral, A., Oome, S., Sander, N., Küfner, I., Nürnberger, T., and Van den Ackerveken, G. 2012. Nontoxic Nep1-like proteins of the downy mildew pathogen Hyaloperonospora arabidopsidis: Repression of necrosisinducing activity by a surface-exposed region. Mol. Plant-Microbe Interact. 25:697-708

Chen, S., Songkumarn, P., Venu, R. C., Gowda, M., Bellizzi, M., Hu, J., Liu, W., Ebbole, D., Meyers, B., Mitchell, T., and Wang, G.-L. 2013. Identification and characterization of in planta-expressed secreted effector proteins from Magnaporthe oryzae that induce cell death in rice. Mol. Plant-Microbe Interact. 26:191-202.

Chooi, Y.-H., and Tang, Y. 2012. Navigating the fungal polyketide chemical space: From genes to molecules. J. Org. Chem. 77:9933-9953.

Collemare, J., Griffiths, S., Iida, Y., Karimi Jashni, M., Battaglia, E., Cox, R. J., and de Wit, P. J. G. M. 2014. Secondary metabolism and biotrophic lifestyle in the tomato pathogen Cladosporium fulvum. PLoS One 9: e85877.

Da Lozzo, E. J., Mangrich, A. S., Rocha, M. E., de Oliveira, M. B., and Carnieri, E. G. 2002. Effects of citrinin on iron-redox cycle. Cell Biochem. Funct. 20:19-29

Dong, S., Kong, G., Qutob, D., Yu, X., Tang, J., Kang, J., Dai, T., Wang, H., Gijzen, M., and Wang, Y. 2012. The NLP toxin family in Phytophthora sojae includes rapidly evolving groups that lack necrosis-inducing activity. Mol. Plant-Microbe Interact. 25:896-909.

Faris, J. D., Zhang, Z., Lu, H., Lu, S., Reddy, L., Cloutier, S., Fellers, J. P., Meinhardt, S. W., Rasmussen, J. B., Xu, S. S., Oliver, R. P., Simons, K. J., and Friesen, T. L. 2010. A unique wheat disease resistance-like gene governs effector-triggered susceptibility to necrotrophic pathogens. Proc. Natl. Acad. Sci. U.S.A. 107:13544-13549.

Feng, B.-Z., Zhu, X.-P., Fu, L., Lv, R.-F., Storey, D., Tooley, P., and Zhang, X.-G. 2014. Characterization of necrosis-inducing 
NLP proteins in Phytophthora capsici. BMC Plant Biol. 14:126. doi: 10.1186/1471-2229-14-126. Published online.

Finn, R. D., Clements, J., and Eddy, S. R. 2011. HMMER web server: Interactive sequence similarity searching. Nucleic Acids Res. 39: W29-W37.

Frías, M., Brito, N., and González, C. 2013. The Botrytis cinerea ceratoplatanin $\mathrm{BcSpl1}$ is a potent inducer of systemic acquired resistance (SAR) in tobacco and generates a wave of salicylic acid expanding from the site of application. Mol. Plant Pathol. 14:191-196.

Frías, M., Brito, N., González, M., and González, C. 2014. The phytotoxic activity of the cerato-platanin BcSpl1 resides in a two-peptide motif on the protein surface. Mol. Plant Pathol. 15:342-351.

Frías, M., González, C., and Brito, N. 2011. BcSpl1, a cerato-platanin family protein, contributes to Botrytis cinerea virulence and elicits the hypersensitive response in the host. New Phytol. 192:483-495.

Friesen, T., and Faris, J. D. 2010. Characterization of the wheat-Stagonospora nodorum disease system: What is the molecular basis of this quantitative necrotrophic disease interaction? Can. J. Plant Pathol. 32:20-28.

Friesen, T. L., Meinhardt, S. W., and Faris, J. D. 2007. The Stagonospora nodorum-wheat pathosystem involves multiple proteinaceous hostselective toxins and corresponding host sensitivity genes that interact in an inverse gene-for-gene manner. Plant J. 51:681-692.

Gallo, A., Ferrara, M., and Perrone, G. 2013. Phylogenetic study of polyketide synthases and nonribosomal peptide synthetases involved in the biosynthesis of mycotoxins. Toxins (Basel) 5:717-742.

Ge, C.-Y., Duan, Y.-B., Zhou, M.-G., and Chen, C.-J. 2013. A protoplast transformation system for gene deletion and complementation in Sclerotinia sclerotiorum. J. Phytopathol. 161:800-806.

Hartman, G. L., Chang, H.-X., and Leandro, L. F. 2015. Research advances and management of soybean sudden death syndrome. Crop Prot. 73:6066.

Hartman, G. L., Huang, Y. H., and Li, S. 2004. Phytotoxicity of Fusarium solani culture filtrates from soybean and other hosts assayed by stem cuttings. Australas. Plant Pathol. 33:9-15.

Irieda, H., Maeda, H., Akiyama, K., Hagiwara, A., Saitoh, H., Uemura, A., Terauchi, R., and Takano, Y. 2014. Colletotrichum orbiculare secretes virulence effectors to a biotrophic interface at the primary hyphal neck via exocytosis coupled with SEC22-mediated traffic. Plant Cell 26: 2265-2281.

Jeong, J. S., Mitchell, T. K., and Dean, R. A. 2007. The Magnaporthe grisea snodprot1 homolog, MSP1, is required for virulence. FEMS (Fed. Eur. Microbiol. Soc.) Microbiol. Lett. 273:157-165.

Jin, H., Hartman, G. L., Nickell, C. D., and Widholm, J. M. 1996. Characterization and purification of a phytotoxin produced by Fusarium solani, the causal agent of soybean sudden death syndrome. Phytopathology 86:277-282.

Kanneganti, T.-D., Huitema, E., Cakir, C., and Kamoun, S. 2006. Synergistic interactions of the plant cell death pathways induced by Phytophthora infestans Nepl-like protein PiNPP1.1 and INF1 elicitin. Mol. Plant-Microbe Interact. 19:854-863.

Keller, O., Kollmar, M., Stanke, M., and Waack, S. 2011. A novel hybrid gene prediction method employing protein multiple sequence alignments. Bioinformatics 27:757-763.

Kelley, B. S., Lee, S.-J., Damasceno, C. M. B., Chakravarthy, S., Kim, B.-D., Martin, G. B., and Rose, J. K. C. 2010. A secreted effector protein (SNE1) from Phytophthora infestans is a broadly acting suppressor of programmed cell death. Plant J. 62:357-366.

Kim, D., Pertea, G., Trapnell, C., Pimentel, H., Kelley, R., and Salzberg, S. L. 2013. TopHat2: Accurate alignment of transcriptomes in the presence of insertions, deletions and gene fusions. Genome Biol. 14:R36R48.

Kim, H.-K., and Yun, S.-H. 2011. Evaluation of potential reference genes for quantitative RT-PCR analysis in Fusarium graminearum under different culture conditions. J. Plant Pathol. 27:301-309.

Kimura, M., Tokai, T., Takahashi-Ando, N., Ohsato, S., and Fujimura, M. 2007. Molecular and genetic studies of Fusarium trichothecene biosynthesis: Pathways, genes, and evolution. Biosci. Biotechnol. Biochem. 71:2105-2123.

Kleemann, J., Rincon-Rivera, L. J., Takahara, H., Neumann, U., Ver Loren van Themaat, E., van der Does, H. C., Hacquard, S., Stüber, K., Will, I., Schmalenbach, W., Schmelzer, E., and O'Connell, R. J. 2012. Sequential delivery of host-induced virulence effectors by appressoria and intracellular hyphae of the phytopathogen Colletotrichum higginsianum. PLoS Pathog. 8:e1002643. doi:10.1371/journal.ppat.1002643.

Knief, C. 2014. Analysis of plant microbe interactions in the era of next generation sequencing technologies. Front. Plant Sci. 5:216.

Kroken, S., Glass, N. L., Taylor, J. W., Yoder, O. C., and Turgeon, B. G. 2003. Phylogenomic analysis of type I polyketide synthase genes in pathogenic and saprobic ascomycetes. Proc. Natl. Acad. Sci. U.S.A. 100 $15670-15675$.

Kuroda, K., Ishii, Y., Takasu, S., Kijima, A., Matsushita, K., Watanabe, M., Takahashi, H., Sugita-Konishi, Y., Sakai, H., Yanai, T., Nohmi, T., Ogawa, K., and Umemura, T. 2013. Cell cycle progression, but not genotoxic activity, mainly contributes to citrinin-induced renal carcinogenesis. Toxicology 311:216-224.

Li, C., Zuo, C., Deng, G., Kuang, R., Yang, Q., Hu, C., Sheng, O., Zhang, S., Ma, L., Wei, Y., Yang, J., Liu, S., Biswas, M. K., Viljoen, A., and Yi, G. 2013. Contamination of bananas with beauvericin and fusaric acid produced by Fusarium oxysporum f. sp. cubense. PLoS One 8:e70226. doi:10.1371/journal.pone.0070226.

Lipka, A. E., Tian, F., Wang, Q., Peiffer, J., Li, M., Bradbury, P. J., Gore, M. A., Buckler, E. S., and Zhang, Z. 2012. GAPIT: Genome association and prediction integrated tool. Bioinformatics 28:2397-2399.

Liu, Z., Faris, J. D., Oliver, R. P., Tan, K.-C., Solomon, P. S., McDonald, M. C., McDonald, B., Nunez, A., S., L., Rasmussen, J. B., and Friesen, T. L. 2009. SnTox3 acts in effector triggered susceptibility to induce disease on wheat carrying the Snn3 gene. PLoS Pathog 5:e1000581. doi: 10.1371/journal.ppat.1000581.

Liu, Z., Zhang, Z., Faris, J. D., Oliver, R. P., Syme, R., McDonald, M. C., McDonald, B. A., Solomon, P. S., Lu, S., Shelver, W. L., Xu, S., and Friesen, T. L. 2012. The cysteine rich necrotrophic effector SnTox1 produced by Stagonospora nodorum triggers susceptibility of wheat lines harboring Snn1. PLoS Pathog. 8:e1002467. doi:10.1371/journal.ppat.1002467.

Ma, S., Niu, H., Liu, C., Zhang, J., Hou, C., and Wang, D. 2013. Expression stabilities of candidate reference genes for RT-qPCR under different stress conditions in soybean. PLoS One 8:e75271. doi:10.1371/journal. pone.0075271.

Mansouri, S., Wuk, R., Rep, M., and Fakhoury, A. M. 2009. Transformation of Fusarium virguliforme, the causal agent of sudden death syndrome of soybean. J. Phytopathol. 157:319-321.

Moffat, C. S., See, P. T., and Oliver, R. P. 2014. Generation of a ToxA knockout strain of the wheat tan spot pathogen Pyrenophora triticirepentis. Mol. Plant Pathol. 15:918-926.

Oliver, R. P., Friesen, T. L., Faris, J. D., and Solomon, P. S. 2012. Stagonospora nodorum: From pathology to genomics and host resistance. Annu. Rev. Phytopathol. 50:23-43.

Oome, S., and Van den Ackerveken, G. 2014. Comparative and functional analysis of the widely occurring family of Nep1-like proteins. Mol. Plant-Microbe Interact. 27:1081-1094.

Petersen, T. N., Brunak, S., von Heijne, G., and Nielsen, H. 2011. SignalP 4.0: Discriminating signal peptides from transmembrane regions. Nat. Methods 8:785-786.

Piper, P. W., and Millson, S. H. 2012. Spotlight on the microbes that produce heat shock protein 90-targeting antibiotics. Open Biol. 2:120138. doi:10.1098/rsob.120138.

Pudake, R. N., Swaminathan, S., Sahu, B. B., Leandro, L. F., and Bhattacharyya, M. K. 2013. Investigation of the Fusarium virguliforme fvtox1 mutants revealed that the FvTox1 toxin is involved in foliar sudden death syndrome development in soybean. Curr. Genet. 59:107117.

Purcell, S., Neale, B., Todd-Brown, K., Thomas, L., Ferreira, M. A. R., Bender, D., Maller, J., Sklar, P., de Bakker, P. I. W., Daly, M. J., and Sham, P. C. 2007. PLINK: A tool set for whole-genome association and population-based linkage analyses. Am. J. Hum. Genet. 81:559-575.

Qutob, D., Kamoun, S., and Gijzen, M. 2002. Expression of a Phytophthora sojae necrosis-inducing protein occurs during transition from biotrophy to necrotrophy. Plant J. 32:361-373.

Ribeiro, S. M., Chagas, G. M., Campello, A. P., and Klüppel, M. L. 1997. Mechanism of citrinin-induced dysfunction of mitochondria. V. Effect on the homeostasis of the reactive oxygen species. Cell Biochem. Funct. 15:203-209.

Santhanam, P., van Esse, H. P., Albert, I., Faino, L., Nürnberger, T., and Thomma, B. P. H. J. 2013. Evidence for functional diversification within a fungal NEP1-like protein family. Mol. Plant-Microbe Interact. 26: 278-286.

Schmittgen, T. D., and Livak, K. J. 2008. Analyzing real-time PCR data by the comparative C(T) method. Nat. Protoc. 3:1101-1108.

Schouten, A., van Baarlen, P., and van Kan, J. A. 2008. Phytotoxic Nep1-like proteins from the necrotrophic fungus Botrytis cinerea associate with membranes and the nucleus of plant cells. New Phytol. 177:493-505.

Shi, G., Friesen, T. L., Saini, J., Xu, S. S., Rasmussen, J. B., and Faris, J. D. 2015. The wheat Snn7 gene confers susceptibilityon recognition of the Parastagonospora nodorum necrotrophic effector SnTox. Plant Genome 8. doi:10.3835/plantgenome2015.3802.0007

Song, Q., Hyten, D. L., Jia, G., Quigley, C. V., Fickus, E. W., Nelson, R. L., and Cregan, P. B. 2013. Development and evaluation of SoySNP50K, a 
high-density genotyping array for soybean. PLoS One 8:e54985. doi: 10.1371/journal.pone.0054985

Sperschneider, J., Dodds, P. N., Gardiner, D. M., Manners, J. M., Singh, K. B., and Taylor, J. M. 2015. Advances and challenges in computational prediction of effectors from plant pathogenic fungi. PLoS Pathog 11: e1004806. doi:10.1001371/journal.ppat.1004806

Srivastava, S. K., Huang, X., Brar, H. K., Fakhoury, A. M., Bluhm, B. H., and Bhattacharyya, M. K. 2014. The genome sequence of the fungal pathogen Fusarium virguliforme that causes sudden death syndrome in soybean. PLoS One 9:e81832.

Stergiopoulos, I., Collemare, J., Mehrabi, R., and De Wit, P. J. G. M. 2013. Phytotoxic secondary metabolites and peptides produced by plant pathogenic Dothideomycete fungi. FEMS (Fed. Eur. Microbiol. Soc.) Microbiol. Rev. 37:67-93.

Strange, R. N. 2007. Phytotoxins produced by microbial plant pathogens. Nat. Prod. Rep. 24:127-144.

Szewczyk, E., Nayak, T., Oakley, C. E., Edgerton, H., Xiong, Y., TaheriTalesh, N., Osmani, S. A., and Oakley, B. R. 2006. Fusion PCR and gene targeting in Aspergillus nidulans. Nat. Protoc. 1:3111-3120.

Tamura, K., Stecher, G., Peterson, D., Filipski, A., and Kumar, S. 2013. MEGA6: Molecular evolutionary genetics analysis version 6.0. Mol. Biol. Evol. 30:2725-2729.

Tan, K.-C., Phan, H. T. T., Rybak, K., John, E., Chooi, Y. H., Solomon, P. S., and Oliver, R. P. 2015. Functional redundancy of necrotrophic effectors-Consequences for expoitation for breeding. Front. Plant Sci. doi:10.3389/fpls.2015.00501

Trapnell, C., Roberts, A., Goff, L., Pertea, G., Kim, D., Kelley, D. R., Pimentel, H., Salzberg, S. L., Rinn, J. L., and Pachter, L. 2012. Differential gene and transcript expression analysis of RNA-seq experiments with TopHat and Cufflinks. Nat. Protoc. 7:562-578.

Vleeshouwers, V. G. A. A., and Oliver, R. P. 2014. Effectors as tools in disease resistance breeding against biotrophic, hemibiotrophic, and necrotrophic plant pathogens. Mol. Plant-Microbe Interact. 27:196-206.

Wicklow, D. T., Jordan, A. M., and Gloer, J. B. 2009. Antifungal metabolites (monorden, monocillins I, II, III) from Colletotrichum graminicola, a systemic vascular pathogen of maize. Mycol. Res. 113: 1433-1442.

Wilson, L. M., Idnurm, A., and Howlett, B. J. 2002. Characterization of a gene ( $s p 1)$ encoding a secreted protein from Leptosphaeria maculans, the blackleg pathogen of Brassica napus. Mol. Plant Pathol. 3:487-493.

Xiang, Y., Scandiani, M. M., Herman, T. K., and Hartman, G. L. 2015. Optimizing production and evaluation conditions for Fusarium virguliforme cell-free toxic filtrates to evaluate soybean genotype responses to isolates causing sudden death syndrome. Plant Dis. 99:502-507.

Yadav, G., Gokhale, R. S., and Mohanty, D. 2009. Towards prediction of metabolic products of polyketide synthases: An in silico analysis. PLOS Comput. Biol. 5:e1000351.

Yang, Y., Zhang, H., Li, G., Li, W., Wang, X., and Song, F. 2009. Ectopic expression of MgSM1, a Cerato-platanin family protein from Magnaporthe grisea, confers broad-spectrum disease resistance in Arabidopsis. Plant Biotechnol. J. 7:763-777.

Yekkour, A., Tran, D., Arbelet-Bonnin, D., Briand, J., Mathieu, F., Lebrihi, A., Errakhi, R., Sabaou, N., and Bouteau, F. 2015. Early events induced by the toxin deoxynivalenol lead to programmed cell death in Nicotiana tabacum cells. Plant Sci. 238:148-157.

Yoshino, K., Irieda, H., Sugimoto, F., Yoshioka, H., Okuno, T., and Takano, Y. 2012. Cell death of Nicotiana benthamiana is induced by secreted protein NIS1 of Colletotrichum orbiculare and is suppressed by a homologue of CgDN3. Mol. Plant-Microbe Interact. 25:625-636.

Zhou, B.-J., Jia, P.-S., Gao, F., and Guo, H.-S. 2012. Molecular characterization and functional analysis of a necrosis- and ethyleneinducing, protein-encoding gene family from Verticillium dahliae. Mol. Plant-Microbe Interact. 25:964-975.

Zhou, L., He, H., Liu, R., Han, Q., Shou, H., and Liu, B. 2014. Overexpression of GmAKT2 potassium channel enhances resistance to soybean mosaic virus. BMC Plant Biol. 14:154.

AUTHOR-RECOMMENDED INTERNET RESOURCE

SoyBase and the Soybean Breeder's Toolbox website: www.soybase.org 